\title{
Polydatin-induced cell apoptosis and cell cycle arrest are potentiated by Janus kinase 2 inhibition in leukemia cells
}

\author{
WEI-JIE CAO ${ }^{1}$, KE WU ${ }^{2}$, CHONG WANG ${ }^{1}$ and DING-MING WAN ${ }^{1}$ \\ ${ }^{1}$ Department of Hematology, The First Affiliated Hospital of Zhengzhou University; \\ ${ }^{2}$ Department of Endodontics, The Fourth Affiliated Hospital of Zhengzhou University, Zhengzhou, Henan 450052, P.R. China
}

Received January 25, 2015; Accepted November 10, 2015

DOI: $10.3892 / \mathrm{mmr} .2016 .4909$

\begin{abstract}
Polydatin (PD), a natural precursor of resveratrol, has a variety of biological activities, including anti-tumor effects. However, the underlying molecular mechanisms of the anti-cancer activity of PD has not been fully elucidated. The present study demonstrated that PD significantly inhibited the proliferation of the MOLT-4 leukemia cell line in a dose- and time-dependent manner by using Cell Counting Kit- 8 assay. PD also dose-dependently increased the apoptotic rate and caused cell cycle arrest in S phase in MOLT-4 cells, as revealed by flow cytometry. In addition, PD dose-dependently decreased the mitochondrial membrane potential and led to the generation of reactive oxygen species in MOLT- 4 cells. Western blot analysis revealed that the expression of anti-apoptotic protein B-cell lymphoma 2 (Bcl-2) was decreased, whereas that of pro-apoptotic protein $\mathrm{Bcl}-2$-associated $\mathrm{X}$ was increased by PD. Furthermore, the expression of two cell cycle regulatory proteins, cyclin D1 and cyclin B1, was suppressed by PD. Of note, the pro-apoptotic and cell cycle-inhibitory effects of PD were potentiated by Janus kinase 2 (JAK2) inhibition. In conclusion, the results of the present study strongly suggested that PD is a promising therapeutic compound for the treatment of leukemia, particularly in combination with JAK inhibitors.
\end{abstract}

\section{Introduction}

Leukemia is the most common malignancy and leading cause of cancer-associated mortality in patients below the age of 20 years (1). Approximately 6,000 new cases of the sub-type acute lymphoblastic leukemia (ALL) are diagnosed in the US each year (1) and the curative rate is approaching $\geq 80 \%$ (2). In spite of this high cure rate, resistant forms of the disease and relapse remain a leading cause of cancer-associated deaths in

Correspondence to: Dr Ding-Ming Wan, Department of Hematology, The First Affiliated Hospital of Zhengzhou University, 1 Jianshe East Road, Zhengzhou, Henan 450052, P.R. China E-mail: chunmei027@126.com

Key words: polydatin, apoptosis, cell cycle, mitochondrial membrane potential, reactive oxygen species, Janus kinase 2 inhibition children. Furthermore, the cure rate of ALL in adults is $~ 50 \%$, which is unsatisfactory (3). Thus, novel treatment strategies, including the development of novel anti-leukemic drugs and the optimization of existing chemotherapeutic treatments, are required to improve current treatments (4).

Due to their low toxicity, naturally occurring phytochemicals have drawn extensive attention as potential drugs for cancer prevention (5). A large number of natural products have previously been discovered for use as chemotherapeutic agents and natural products offer a pool for the discovery of novel anti-cancer agents, which is sourced by current research. Polydatin (PD) is a stilbenoid compound isolated from the root of Polygonum cuspidatum (6). PD has been shown to have multiple beneficial therapeutic properties, including cardioprotective (7-9), hepatoprotective (10), neuroprotective (11) and anti-inflammatory (12) effects. PD has also been reported to have anti-cancer effects with activity against colon (13) and lung (14) cancer as well as nasopharyngeal carcinoma (15). However, to the best of our knowledge, the effects of PD on human leukemic cells have yet not been studied. In the present study, the effects of PD on the proliferation, cell cycle distribution and apoptosis of the MOLT-4 human ALL cell line were investigated. As the JAK2-STAT3 signaling pathway is known to promote cell growth (16) and confer resistance to apoptosis in leukemic cells (17), it was also examined whether the JAK2-STAT3 pathway is involved in PD-induced apoptosis and cell cycle arrest.

\section{Materials and methods}

Chemicals. PD was supplied by LKT Laboratories, Inc. (St Paul, MN, USA; cat. no. P5845) and a 10-mM stock solution in dimethysulfoxide (DMSO) was prepared, which was diluted with medium to the appropriate concentrations for use in the assays. A Cell Counting Kit-8 (CCK-8) was purchased from Signalway Antibody LLC (College Park, MD, USA) and an Annexin V-conjugated Alexa Fluor 488 apoptosis detection kit was obtained from 7SeaPharmTech (Shanghai, China). Primary antibodies against B-cell lymphoma 2 (Bcl-2) and Bcl-2-associated X (Bax) were purchased from Santa Cruz Biotechnology, Inc. (Dallas, TX, USA), antibodies against cyclin B1, phosphorylated signal transducer and activator of transcription (p-STAT3) and STAT3 were from Abcam (Cambridge, UK), and antibodies 
against cyclin D1, p-Janus kinase (JAK)2, JAK2 and GAPDH were from Cell Signaling Technology Inc. (Danvers, MA, USA). Secondary antibodies were purchased from Beyotime Institute of Biotechnology (Haimen, China). The Pierce bicinchoninic acid (BCA) Protein Assay kit was supplied by Thermo Fisher Scientific (Waltham, MA, USA) and the Immobilon ${ }^{\mathrm{TM}}$ Western Chemiluminescent Horseradish Peroxidase substrate (cat. no. WBKLS0100) was obtained from EMD Millipore (Billerica, MA, USA). AG490 was obtained from Beyotime Institute of Biotechnology and dissolved with DMSO to make a stock at $10 \mathrm{mM}$. Cells were treated with $10 \mathrm{mM}$ AG490 as indicated.

Cell culture. The MOLT- 4 cell line was obtained from the American Type Culture Collection (Manassas, VA, USA) and maintained in monolayer culture in RPMI-1640 medium Hyclone (Logan, UT, USA), supplemented with $10 \%$ fetal calf serum, $2 \mathrm{mmol} / \mathrm{l}$ glutamine, $100 \mu \mathrm{g} / \mathrm{ml}$ streptomycin and $100 \mathrm{U} / \mathrm{ml}$ penicillin (all Gibco; Thermo Fisher Scientific Inc., Waltham, MA, USA). at $37^{\circ} \mathrm{C}$ in a humidified atmosphere containing $5 \% \mathrm{CO}_{2}$. Cells in the logarithmic growth phase were used in all experiments.

Cell proliferation assay. The effects of PD on the proliferation of MOLT- 4 cells were determined using the CCK- 8 kit according to the manufacturer's instructions. In brief, the cells were seeded in 96-well plates at a density of $5 \times 10^{3}$ per well. The cells were then treated with DMSO $(0.1 \%)$ or PD $(0.5,1$, $2,4,10$ or $20 \mu \mathrm{M}$ ) at $37^{\circ} \mathrm{C}$. Following $0,6,12,24,48$ or $72 \mathrm{~h}$ of incubation, $10 \mu \mathrm{l} \mathrm{CCK-8} \mathrm{was} \mathrm{added} \mathrm{to} \mathrm{each} \mathrm{well,} \mathrm{followed}$ by further incubation for $1 \mathrm{~h}$. The optical density was then determined at $450 \mathrm{~nm}$ to calculate the proliferative index.

Assessment of apoptosis. The apoptotic rate of MOLT-4 cells was analyzed using an Annexin V-propidium iodide (PI)-based immunofluorescence apoptosis detection kit according to the manufacturer's instructions. In brief, the cells were incubated in six-well plates $\left(3 \times 10^{5}\right.$ cells/well) for $24 \mathrm{~h}$. The cells were then treated with DMSO or PD $(1,4$ or $20 \mu \mathrm{M})$ for $24 \mathrm{~h}$. Approximately $1 \times 10^{5}$ cells were harvested, washed in phosphate-buffered saline (PBS) and incubated with $5 \mu \mathrm{l}$ Annexin V stain and PI at room temperature for $10 \mathrm{~min}$. Fluorescence was measured using a FACSCalibur flow cytometer (BD Biosciences, Franklin Lakes, NJ, USA). Annexin V-positive and PI-negative cells were regarded as apoptotic.

Cell cycle analysis. Approximately $1 \times 10^{6}$ cells were harvested and washed three times with PBS and fixed in $70 \%$ cold ethanol for $\geq 4 \mathrm{~h}$. The cells were then re-suspended in DNA staining solution $(50 \mu \mathrm{g} / \mathrm{ml} \mathrm{PI}, 100 \mu \mathrm{g} / \mathrm{ml}$ RNase A and $0.1 \%$ Triton X-100 in PBS; all from Jrdun Biotech (Shanghai, China), followed by incubation at room temperature for $30 \mathrm{~min}$. The DNA content was then determined using a FACSCalibur flow cytometer (BD Biosciences). The cell cycle distribution was calculated from 10,000 cells using CellQuest Pro (BD Biosciences) and Modfit software 3.2 (Verity Software House, Topsham, ME, USA).

Assessment of mitochondrial membrane potential (MMP). The MMP was evaluated by assessing the accumulation of rhodamine 123 (Molecular Probes, Eugene, OR, USA) according to a method described previously (18). Briefly, the cells were incubated in six-well plates $\left(3 \times 10^{5}\right.$ cells/well) for $24 \mathrm{~h}$ and then treated with DMSO or PD $(1,4$ or $20 \mu \mathrm{M})$ for $24 \mathrm{~h}$. Cells were harvested, washed in PBS and incubated with $0.5 \mu \mathrm{M}$ rhodamine 123 at $37^{\circ} \mathrm{C}$ for $15 \mathrm{~min}$. Fluorescence was measured using a FACSCalibur flow cytometer (BD Biosciences) with an excitation wavelength of $485 \mathrm{~nm}$ and an emission wavelength of $520 \mathrm{~nm}$.

Evaluation of reactive oxygen species (ROS) by flow cytometry using dihydroethidium (DHE). DHE (Vigorous Biotechnology Beijing Co., Ltd., Beijing, China) was used for the flow cytometric assessment of superoxide production as described previously (19). DHE is rapidly oxidized to ethidium, a red fluorescent compound, by $\mathrm{H}_{2} \mathrm{O}_{2}$ (in the presence of peroxidase) and superoxide. Cells were harvested, washed with PBS and incubated with $50 \mu \mathrm{M}$ DHE at room temperature for $5 \mathrm{~min}$. Fluorescence was measured using a FACSCalibur flow cytometer (BD Biosciences). DHE fluorescence in cells was evaluated using CellQuest software (BD Biosciences).

Western blot analysis. Western blot analyses was performed according to a previously described method (13). Cells were treated with DMSO $(0.1 \%)$ or $20 \mu \mathrm{M}$ PD and incubated for 1 or $24 \mathrm{~h}$. Following lysis in RIPA lysis buffer (Jrdun Biotech), the protein concentration was quantified using the Pierce BCA Protein Assay kit following the manufacturer's instructions. Equal amounts $(30 \mu \mathrm{g})$ of protein were separated by electrophoresis on 10 or $15 \%$ sodium dodecyl sulfate-polyacrylamide gels (Jrdun Biotech) and transferred onto nitrocellulose membranes (EMD Millipore). Following blocking with 5\% non-fat milk, the membranes were incubated with the desired primary antibodies overnight at the following dilutions: p-JAK2 (1:1,000; Cell Signaling Technology Inc.; cat. no. 3776); JAK2 (1:1,000; Cell Signaling Technology Inc.; cat. no. 3230); p-STAT3 (1:1,000; Abcam; cat. no. Ab76315); STAT3 (1:1,000; Abcam; cat. no. Ab119352); Bax, (1:100; Santa Cruz Biotechnology Inc.; cat. no. Sc-493); Bcl-2 (1:150; Santa Cruz Biotechnology Inc.; cat. no. Sc-492); cyclin B1 (1:20,000; Abcam; cat. no. Ab32053); cyclin D1 (1:1,000; Cell Signaling Technology Inc.; cat. no. 2922) and GAPDH (1:1,500 Cell Signaling Technology Inc., cat. no. 5174). Subsequently, the membranes were incubated with the appropriate secondary antibodies: Horseradish peroxidase (HRP) conjugated goat-anti-rabbit antibody (1:1,000; Beyotime Institute of Biotechnology; cat. no. A0208); HRP-conjugated goat-anti mouse antibody $(1: 1,000$; Beyotime Institute of Biotechnology; cat. no. A0216). The membranes were exposed to X-ray film (Kodak XAR-2, Rochester, NY, USA). The immunoreactive bands were visualized using the Immobilon ${ }^{\mathrm{TM}}$ Western Chemiluminescent Horseradish Peroxidase substrate (EMD Millipore) according to the manufacturer's instructions.

Statistical analysis. Values are expressed as the mean \pm standard deviation. Statistical analysis was performed by multifactorial analysis of variance using SPSS software 17.0 


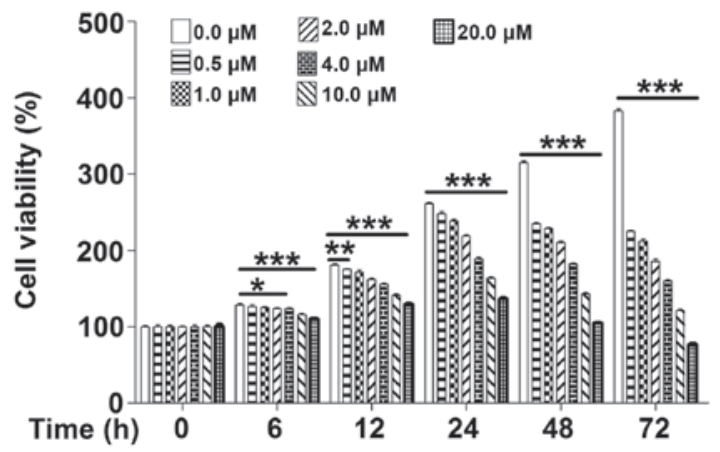

Figure 1. PD dose-and time-dependently reduces the viability of MOLT-4 cells. Cell viability of MOLT- 4 cells was examined using a Cell Counting Kit 8 assay after treatment with PD $(0,0.5,1,2,4,10$ or $20 \mu \mathrm{M})$ for $0,6,12,24$, 48 or $72 \mathrm{~h}$. Values are expressed as the mean \pm standard deviation $(\mathrm{n}=3)$. PD, polydatin. ${ }^{*} \mathrm{P}<0.05,{ }^{* *} \mathrm{P}<0.01$ and ${ }^{* * * *} \mathrm{P}<0.01$ compared with $0.0 \mu \mathrm{M}$.

\section{A}

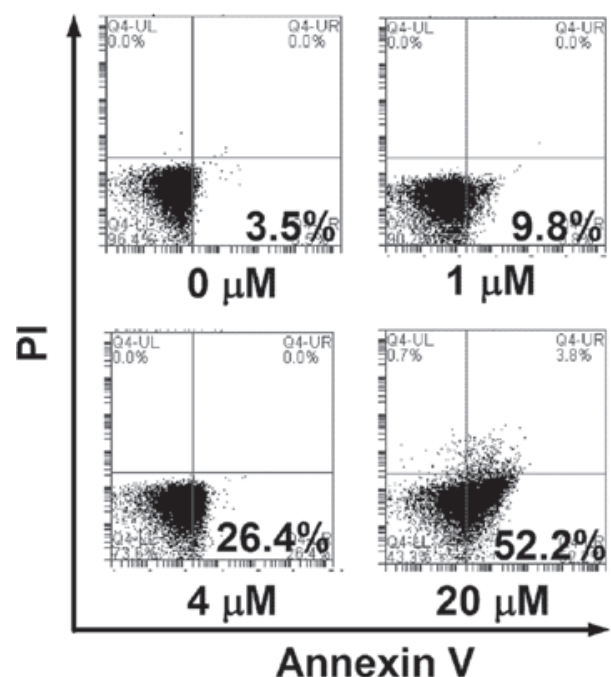

B

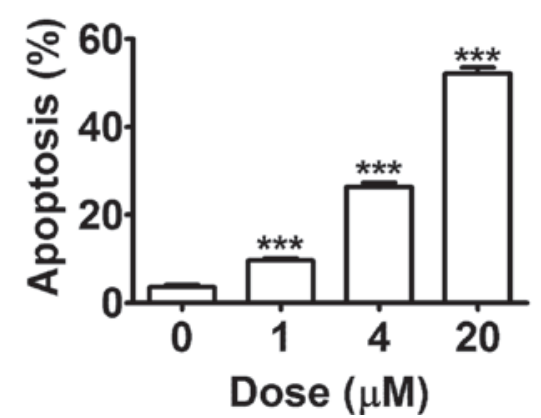

Figure 2. PD increases the apoptotic rate of MOLT-4 cells. (A) Representative images and (B) quantification of cell apoptosis examined by flow cytometry in MOLT-4 cells after treatment with PD $(0,1,4$ or $20 \mu \mathrm{M})$ for $24 \mathrm{~h}$. Values are expressed as the mean \pm standard deviation. ${ }^{* * * *} \mathrm{P}<0.001$ compared with control. PD, polydatin; PI, propidium iodide.

(SPSS, Inc., Chicago, IL, USA). P $<0.05$ was considered to indicate a statistically significant difference.

\section{Results}

PD inhibits the proliferation ofleukemia cells. The cytotoxicity of PD on MOLT-4 leukemia cells was determined using the CCK8 assay. In the absence of PD, MOLT-4 proliferated in an exponential manner, while PD inhibited the cell proliferation
A

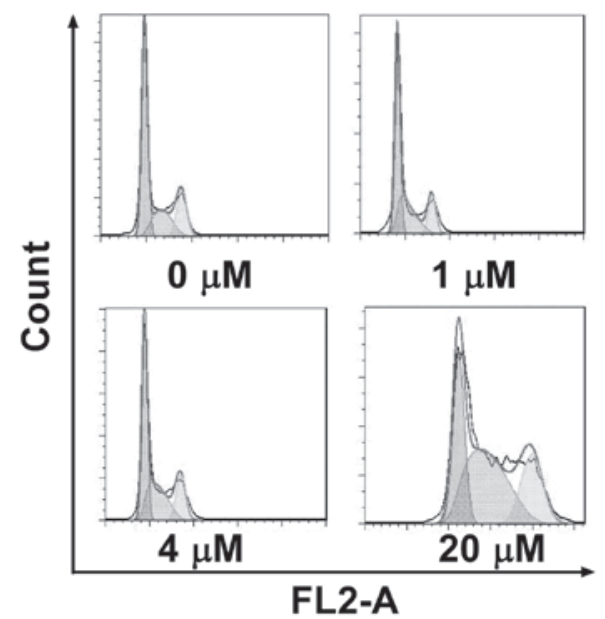

B

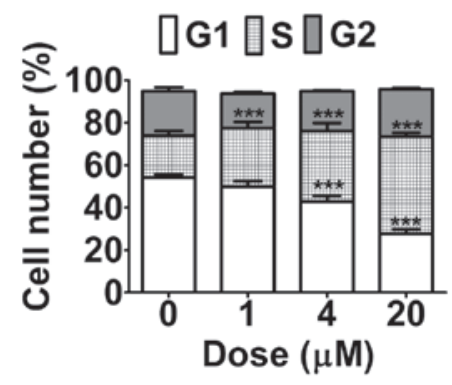

Figure 3.Polydatin induces S-phase arrest of MOLT-4 cells. (A) Representative images and (B) percentage of cells in each phase of the cell cycle examined by flow cytometry in MOLT- 4 cells after treatment with PD $(0,1,4$ or $20 \mu \mathrm{M})$ for $24 \mathrm{~h}$. Values are expressed as the mean \pm standard deviation. ${ }^{* * *} \mathrm{P}<0.001$ compared with control. The experiments were performed three times.

in a dose-dependent manner, as well as a time-dependent manner at 6-12 $\mathrm{h}$ (Fig. 1). These results indicated that, due to its marked anti-proliferative effects, PD may be suitable for the treatment of leukemia.

$P D$ induces apoptosis in leukemia cells. To investigate the underlying mechanism of PD-induced inhibition of leukemia cell growth, MOLT-4 cells were incubated with various concentrations of PD for $24 \mathrm{~h}$ and their apoptotic rate was assessed by flow cytometry. PD was shown to induce apoptosis in leukemia cells in a dose-dependent manner $(\mathrm{P}<0.001)$ (Fig. 2A). The apoptotic rate increased from $3.63 \pm 0.42 \%$ in the control group to $9.67 \pm 0.42,26.33 \pm 1.00$ and $52.13 \pm 1.30 \%$ following incubation with 1,4 and $20 \mu \mathrm{M}$ PD for $24 \mathrm{~h}$, respectively (Fig. 2B). These results suggested that PD induced apoptotic cell death in leukemia cells.

$P D$ induces cell-cycle arrest in $S$ phase in leukemia cells. To determine whether interference with cell-cycle progression is among the underlying mechanisms of PD-induced growth inhibition of leukemia cells, the effects of PD on cell cycle progression were examined in exponentially growing MOLT-4 cells. Treatment of cells with various concentrations of PD for $24 \mathrm{~h}$ resulted in an increased accumulation of cells in S phase and a corresponding decrease in the G1-phase population (Fig. 3A). In the absence of PD, the S-phase population was $19.73 \pm 2.14 \%$ and the G1-phase population was $54.25 \pm 1.56 \%$. Following PD treatment of MOLT- 4 cells at 1,4 and $20 \mu \mathrm{M}$, the 
A

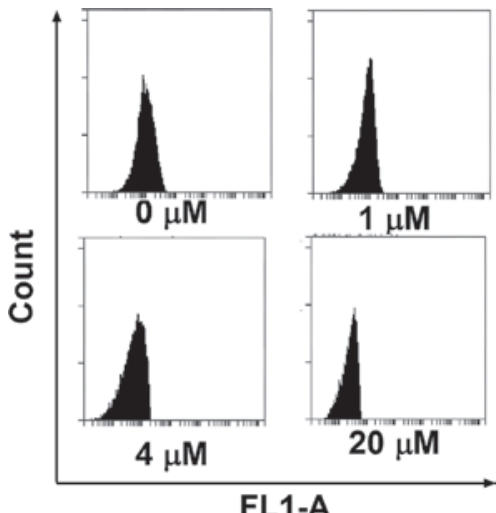

B

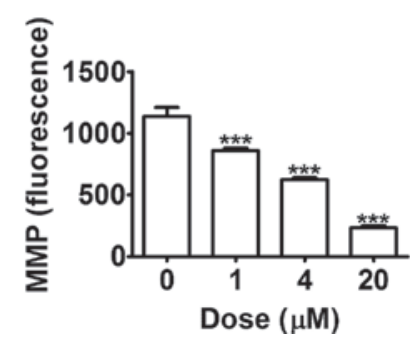

Figure 4. PD decreases MMP in MOLT-4 cells. (A) Representative images and (B) percentage of MMP fluorescence examined by flow cytometry in MOLT- 4 cells after treatment with PD $(0,1,4$ or $20 \mu \mathrm{M})$ for $24 \mathrm{~h}$. Values are expressed as the mean \pm standard deviation. ${ }^{* * *} \mathrm{P}<0.001$ compared with control. PD, polydatin; MMP, mitochondrial membrane potential.

S-phase population was increased to $27.58 \pm 2.91,33.25 \pm 3.84$ and $45.81 \pm 1.86 \%$, whereas the G1-phase population was decreased to $49.87 \pm 2.56,42.80 \pm 2.88$ and $27.25 \pm 2.25 \%$ (Fig. 3B). This result revealed that PD inhibited cell proliferation by inducing cell-cycle arrest.

PD decreases the MMP in leukemia cells. Mitochondria have key roles in activating apoptosis in mammalian cells (20). The MMP is regarded as a measure for mitochondrial function and it is decreased during apoptosis (21). The results of the present study revealed that treatment of MOLT- 4 cells with PD for $24 \mathrm{~h}$ resulted in a decrease in the MMP (Fig. 4A). The MMP decreased from 1,136 \pm 73 in the control group to $859.0 \pm 21.1$, $625.0 \pm 15.7$ and $231.9 \pm 19.3$ following incubation with 1,4 and $20 \mu \mathrm{M}$ PD for $24 \mathrm{~h}(\mathrm{P}<0.001)$ (Fig. 4B). These results demonstrated that PD induced apoptosis in leukemia cells through the mitochondrial pathway.

$P D$ increases ROS in leukemia cells. Mitochondria-dependent apoptosis is often mediated by ROS (22). To examine the levels of ROS in MOLT-4 cells, DHE staining was used. Treatment of cells with PD for $24 \mathrm{~h}$ resulted in an increase of ROS in a dose-dependent manner $(\mathrm{P}<0.001)$ (Fig. 5A). ROS levels in leukemia cells increased from 7,529 $\pm 5,618$ in the control group to $22,448 \pm 757,69,669 \pm 2,010$ and $154,994 \pm 1,587$ following incubation with 1, 4 and $20 \mu \mathrm{M}$ PD for $24 \mathrm{~h}$ (Fig. 5B). These results demonstrated that $\mathrm{PD}$ treatment led to the generation of ROS to initiate mitochondria-dependent apoptosis in leukemia cells.

PD-induced apoptosis of leukemia cells is potentiated by inhibition of JAK2-STAT3 signaling. Due to the observed
A

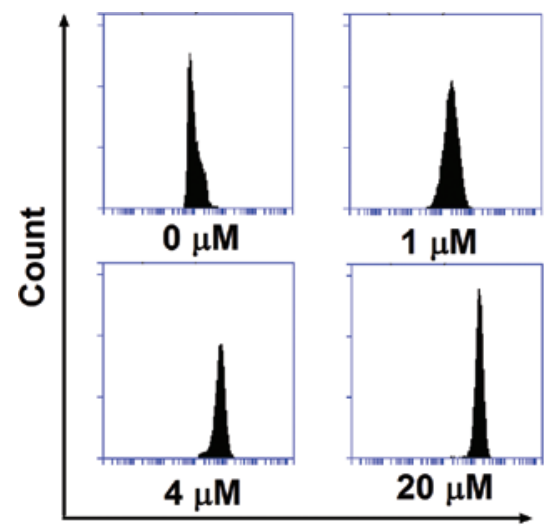

B

FL2-A

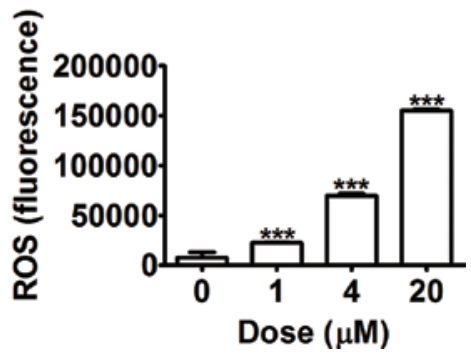

Figure 5. PD decreases ROS in MOLT-4 cells. (A) Representative images and (B) quantification of ROS fluorescence examined by flow cytometry in MOLT-4 cells after treatment with PD $(0,1,4$ or $20 \mu \mathrm{M})$ for $24 \mathrm{~h}$. Values are expressed as the mean \pm standard deviation. ${ }^{* * *} \mathrm{P}<0.001$ compared with control. PD, polydatin; ROS, reactive oxygen species.
A

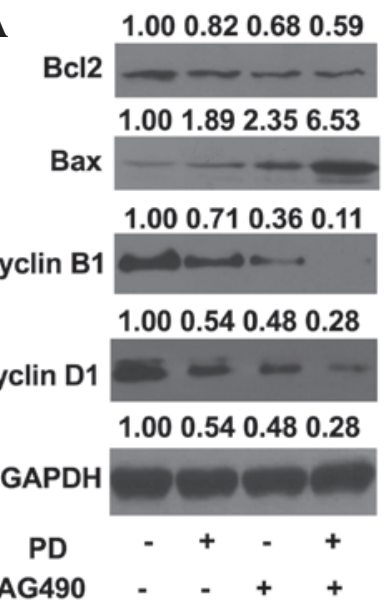

B
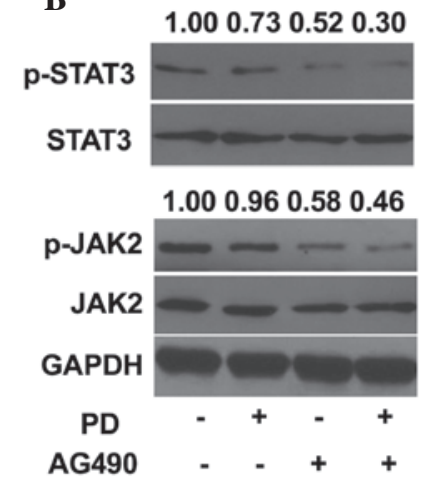

Figure 6. PD potentiates the effects of JAK2 inhibition on cell apoptosis and cell cycle arrest in MOLT-4 cells. (A) The expression levels of Bcl2, Bax, cyclin B1 and cyclin D1 following PD treatment for $24 \mathrm{~h}$, and (B) the expression levels of p-JAK2, JAK2, p-STAT3 and STAT3 after PD treatment for $1 \mathrm{~h}$ in the absence or presence of $10 \mathrm{nM}$ JAK2 inhibitor AG490 were examined by western blotting. GAPDH was used as loading control. p-JAK2, phosphorylated Janus kinase 2; STAT3, signal transducer and activator of transcription; Bcl2, B-cell lymphoma 2; Bax, Bcl2-associated X protein; PD, polydatin.

effects of PD on apoptosis and S-phase arrest in leukemia cells, the impact of PD on the expression of Bcl-2 and Bax, two key regulatory proteins of apoptosis, as well as cyclin B1 and cyclin D1, two key cell cycle-regulators, were examined by western blot analysis. The results showed that the expression of anti-apoptotic protein $\mathrm{Bcl}-2$ as well as cell cycle proteins cyclin B1 and cyclin D1 was significantly decreased, while the expression of pro-apoptotic protein Bax was significantly 
increased following treatment of MOLT-4 cells with PD for $24 \mathrm{~h}$ (Fig. 6A). Inhibition of JAK2 activity by the specific tyrosine kinase inhibitor AG490 is known to selectively block leukemic cell growth in vitro and in vivo by inducing programmed cell death (23). The present study examined whether the JAK2-STAT3 pathway is involved in PD-induced apoptosis and cell cycle arrest. Of note, the $\mathrm{Bax} / \mathrm{Bcl}-2$ ratio, an indicator of apoptosis (24), was markedly increased in MOLT-4 cells following combined treatment with PD and AG490 as compared with that following treatment with either drug alone. In parallel, the expression of cyclin B1 and cyclin D1 was also markedly decreased following combined treatment with PD and AG490. Furthermore, combined treatment with PD and AG490 for $1 \mathrm{~h}$ potently reduced the levels of p-STAT3 and p-JAK2, indicating the de-activation of the JAK2-STAT3 signaling pathway (Fig. 6B). This result suggested that PD and JAK2 inhibition may have synergistic effects with regard to the induction of apoptosis in leukemia cells.

\section{Discussion}

PD is a natural precursor of resveratrol. Numerous studies have suggested that resveratrol is a promising candidate for cancer chemoprevention and therapy (25). However, it is difficult to reach a therapeutically relevant level in vivo, since resveratrol is readily metabolized and eliminated from the body (26). As resveratrol derivative with a glucopyranoside ring substitution of the hydroxyl group in position three, PD features enhanced stability and water solubility, and is able to enter cells via glucose transporters (27). Due to these properties, PD is more easily absorbed in the intestinal tract than resveratrol. PD has been shown to have cytotoxic effects on various cancer cell lines, including colon (13), lung (14) and nasopharyngeal (15) cancer cells; however, the underlying mechanism of action has largely remained elusive. The present study showed that PD, exerted anti-proliferative effects via inducing cell cycle arrest and induced mitochondria-mediated apoptosis in MOLT-4 leukemia cell lines, which was potentiated by a JAK2 inhibitor.

Apoptosis is a highly organized form of cell death, via which cells which have suffered significant damage are eliminated (28). Apoptosis can be triggered through either a death receptor-mediated extrinsic pathway or a mitochondria-mediated intrinsic pathway (29). It is desirable to discover drugs which selectively induce apoptosis in cancer cells through triggering cancer-specific upstream mechanisms. As these pathways are frequently altered in tumors, is may be possible to selectively induce apoptosis in cancer cells or sensitize them to established cytotoxic agents (30). The present study demonstrated that PC triggers apoptosis in human leukemia cells through the mitochondria-mediated intrinsic pathway, rendering it a promising drug candidate for leukemia therapy.

ROS are mediators of numerous intracellular signaling cascades; however, upon overproduction, they may induce the collapse of the mitochondrial membrane potential, which triggers a series of mitochondria-associated events, including apoptosis (31). The present study demonstrated that PD treatment markedly enhanced ROS production in parallel with mitochondria-mediated leukemia-cell apoptosis; therefore, it is likely that apoptosis was, at least in part, triggered by ROS generation.
The proliferation of mammalian cells is driven by the core cell cycle machinery comprising cyclin and cyclin-dependent kinase (CDK) complexes (32). D-type cyclins, the ultimate recipients of numerous oncogenic pathways, are key signaling molecules and represent targets for cancer treatments (33). Among them, cyclin D1 is dispensable with regard to normal physiological processes in adults, but is required for tumor maintenance (34). Cyclin D1 levels must be suppressed during the $\mathrm{S}$ phase for efficient DNA synthesis and must be re-induced during the $\mathrm{G} 2$ phase to support cell proliferation (35). The present study showed that PD inhibited the expression of cyclin D1 and cyclin B1 and caused cell-cycle arrest in S phase, which was the underlying mechanism of its anti-proliferative effects.

Numerous cancer types, including hematological malignancies, have been associated with constitutive activation of members of the STAT family, whereas JAK-mediated tyrosine phosphorylation is often required for transcriptional activation of STAT proteins (36). A unique somatic gain-of-function mutation in JAK2 (JAK2 V617F) was found in $>90 \%$ of patients with polycythaemia vera and in $50 \%$ of those with essential thrombocythemia and primary myelofibrosis $(37,38)$. The combination of JAK2 inhibitors with inhibitors of downstream effectors, including Bcl-2/Bcl extra large (ABT-737) has been suggested to enhance the efficacy of polycythaemia vera treatments (39). This strategy is thought to be effective for the treatment of subsets of ALL featuring dysregulation of JAK/STAT signaling. The present study found that a JAK2 inhibitor indeed potentiated the apoptotic and cell cycle-inhibitory effects of PD.

In conclusion, the results of the present study demonstrated that PD-induced apoptosis of human leukemia cells is mediated by the generation of ROS in mitochondria. Furthermore, the inhibition of cyclin D1 by PD was shown to be accountable for its anti-proliferative effects. The present study suggested that treatment with PD and JAK2 inhibitor holds promise as a novel and effective combination chemotherapy for leukemia.

\section{Acknowledgements}

The present study was supported by the National Natural Science Foundation of China (grant no. 81300418) and the Youth Innovation Fund of the First Affiliated Hospital of Zhengzhou University.

\section{References}

1. Siegel R, Ma J, Zou Z and Jemal A: Cancer statistics, 2014. CA Cancer J Clin 64: 9-29, 2014.

2. Gregers J, Gréen H, Christensen IJ, Dalhoff K, Schroeder H, Carlsen N, Rosthoej S, Lausen B, Schmiegelow K and Peterson C: Polymorphisms in the ABCB1 gene and effect on outcome and toxicity in childhood acute lymphoblastic leukemia. Pharmacogenomics J 15: 372-379, 2015.

3. Neumann M, Vosberg S, Schlee C, Heesch S, Schwartz S, Gökbuget N, Hoelzer D, Graf A, Krebs S, Bartram I, et al: Mutational spectrum of adult T-ALL. Oncotarget 6: 2754-2766, 2015.

4. Pui $\mathrm{CH}$ and Evans WE: Acute lymphoblastic leukemia. N Engl J Med 339: 605-615, 1998

5. Mehta RG and Pezzuto JM: Discovery of cancer preventive agents from natural products: From plants to prevention. Curr Oncol Rep 4: 478-486, 2002.

6. Du QH, Peng $\mathrm{C}$ and Zhang $\mathrm{H}$ : Polydatin: A review of pharmacology and pharmacokinetics. Pharm Biol 51: 1347-1354, 2013. 
7. Zhang Q, Tan Y, Zhang N and Yao F: Polydatin prevents angiotensin II-induced cardiac hypertrophy and myocardial superoxide generation. Exp Biol Med (Maywood), 2014.

8. Dong M, Ding W, Liao Y, Liu Y, Yan D, Zhang Y, Wang R, Zheng N, Liu S and Liu J: Polydatin prevents hypertrophy in phenylephrine induced neonatal mouse cardiomyocytes and pressure-overload mouse models. Eur J Pharmacol 746: 186-197, 2015 .

9. Ding W, Dong M, Deng J, Yan D, Liu Y, Xu T and Liu J: Polydatin attenuates cardiac hypertrophy through modulation of cardiac $\mathrm{Ca} 2+$ handling and calcineurin-NFAT signaling pathway. Am J Physiol Heart Circ Physiol 307: H792-H802, 2014.

10. Zhang Q, Tan Y, Zhang N and Yao F: Polydatin supplementation ameliorates diet-induced development of insulin resistance and hepatic steatosis in rats. Mol Med Rep 11: 603-610, 2015.

11. Sun J, Qu Y, He H, Fan X, Qin Y, Mao W and Xu L: Protective effect of polydatin on learning and memory impairments in neonatal rats with hypoxic-ischemic brain injury by up-regulating brain-derived neurotrophic factor. Mol Med Rep 10: 3047-3051, 2014.

12. Ravagnan G, De Filippis A, Cartenì M, De Maria S, Cozza V, Petrazzuolo M, Tufano MA and Donnarumma G: Polydatin, a natural precursor of resveratrol, induces $\beta$-defensin production and reduces inflammatory response. Inflammation 36: 26-34, 2013.

13. De Maria S, Scognamiglio I, Lombardi A, Amodio N, Caraglia $\mathrm{M}$, Cartenì $\mathrm{M}$, Ravagnan $\mathrm{G}$ and Stiuso $\mathrm{P}$ : Polydatin, a natural precursor of resveratrol, induces cell cycle arrest and differentiation of human colorectal Caco-2 cell. J Transl Med 11: 264, 2013.

14. Zhang Y, Zhuang Z, Meng Q, Jiao Y, Xu J and Fan S: Polydatin inhibits growth of lung cancer cells by inducing apoptosis and causing cell cycle arrest. Oncol Lett 7: 295-301,2014.

15. Liu H, Zhao S, Zhang Y, Wu J, Peng H, Fan J and Liao J: Reactive oxygen species-mediated endoplasmic reticulum stress and mitochondrial dysfunction contribute to polydatin-induced apoptosis in human nasopharyngeal carcinoma CNE cells. J Cel Biochem 112: 3695-3703, 2011.

16. Takemoto S, Mulloy JC, Cereseto A, Migone TS, Patel BK, Matsuoka M, Yamaguchi K, Takatsuki K, Kamihira S, White JD, et al: Proliferation of adult T cell leukemia/lymphoma cells is associated with the constitutive activation of JAK/STAT proteins Proc Natl Acad Sci USA 94: 13897-13902, 1997.

17. Alas S and Bonavida B: Rituximab inactivates signal transducer and activation of transcription 3 (STAT3) activity in B-non-Hodgkin's lymphoma through inhibition of the interleukin 10 autocrine/paracrine loop and results in down-regulation of Bcl-2 and sensitization to cytotoxic drugs. Cancer Res 61: 5137-5144, 2001

18. Wu EY, Smith MT, Bellomo G and Di Monte D: Relationships between the mitochondrial transmembrane potential, ATP concentration and cytotoxicity in isolated rat hepatocytes. Arch Biochem Biophys 282: 358-362, 1990.

19. Medjkane S, Perichon M, Marsolier J, Dairou J and Weitzman JB: Theileria induces oxidative stress and HIF $1 \alpha$ activation that are essential for host leukocyte transformation. Oncogene 33: 1809-1817, 2014

20. Wang $\mathrm{C}$ and Youle RJ: The role of mitochondria in apoptosis. Annu Rev Genet 43: 95-118, 2009.

21. Gottlieb E, Armour SM, Harris $\mathrm{MH}$ and Thompson $\mathrm{CB}$ : Mitochondrial membrane potential regulates matrix configuration and cytochrome c release during apoptosis. Cell Death Differ 10: 709-717, 2003
22. Herrera B, Alvarez AM, Sánchez A, Fernández M, Roncero C, Benito $\mathrm{M}$ and Fabregat I: Reactive oxygen species (ROS) mediates the mitochondrial-dependent apoptosis induced by transforming growth factor (beta) in fetal hepatocytes. FASEB J 15: 741-751, 2001.

23. Meydan N, Grunberger T, Dadi H, Shahar M, Arpaia E, Lapidot Z, Leeder JS, Freedman M, Cohen A, Gazit A, et al: Inhibition of acute lymphoblastic leukaemia by a Jak-2 inhibitor. Nature 379: 645-648, 1996

24. Xu JY, Meng QH, Chong Y, Jiao Y, Zhao L, Rosen EM and Fan S: Sanguinarine inhibits growth of human cervical cancer cells through the induction of apoptosis. Oncol Rep 28: 2264-2270, 2012.

25. Singh CK, Ndiaye MA and Ahmad N: Resveratrol and cancer: Challenges for clinical translation. Biochim Biophys Acta 1852: 1178-1185, 2015.

26. Francioso A, Mastromarino P, Masci A, d'Erme M and Mosca L: Chemistry, stability and bioavailability of resveratrol. Med Chem 10: 237-245, 2014.

27. Krasnow MN and Murphy TM: Polyphenol glucosylating activity in cell suspensions of grape (Vitis vinifera). J Agric Food Chem 52: 3467-3472, 2004.

28. Daniel PT, Koert U and Schuppan J: Apoptolidin: Induction of apoptosis by a natural product. Angew Chem Int Ed Engl 45: 872-893, 2006

29. Circu ML and Aw TY: Glutathione and modulation of cell apoptosis. Biochim Biophys Acta 1823: 1767-1777, 2012.

30. Ghobrial IM, Witzig TE and Adjei AA: Targeting apoptosis pathways in cancer therapy. CA Cancer J Clin 55: 178-194, 2005.

31. Qu K, Shen NY, Xu XS, Su HB, Wei JC, Tai MH, Meng FD, Zhou L, Zhang YL and Liu C: Emodin induces human T cell apoptosis in vitro by ROS-mediated endoplasmic reticulum stress and mitochondrial dysfunction. Acta Pharmacol Sin 34: 1217-1228, 2013

32. Malumbres M and Barbacid M: Cell cycle, CDKs and cancer: A changing paradigm. Nat Rev Cancer 9: 153-166, 2009.

33. Musgrove EA, Caldon CE, Barraclough J, Stone A and Sutherland RL: Cyclin D as a therapeutic target in cancer. Nat Rev Cancer 11: 558-572, 2011.

34. Choi YJ, Li X, Hydbring P, Sanda T, Stefano J, Christie AL, Signoretti S, Look AT, Kung AL, von Boehmer H and Sicinski P: The requirement for cyclin $\mathrm{D}$ function in tumor maintenance. Cancer Cell 22: 438-451, 2012.

35. Yang K, Hitomi M and Stacey DW: Variations in cyclin D1 levels through the cell cycle determine the proliferative fate of a cell. Cell Div 1: 32, 2006.

36. Vainchenker W and Constantinescu SN: JAK/STAT signaling in hematological malignancies. Oncogene 32: 2601-2613, 2013.

37. James C, Ugo V, Le Couédic JP, Staerk J, Delhommeau F, Lacout C, Garçon L, Raslova H, Berger R, Bennaceur-Griscelli A, et al: A unique clonal JAK2 mutation leading to constitutive signalling causes polycythaemia vera. Nature 434: 1144-1148, 2005

38. Levine RL, Wadleigh M, Cools J, Ebert BL, Wernig G, Huntly BJ, Boggon TJ, Wlodarska I, Clark JJ, Moore S, et al: Activating mutation in the tyrosine kinase JAK2 in polycythemia vera, essential thrombocythemia, and myeloid metaplasia with myelofibrosis. Cancer Cell 7: 387-397, 2005.

39. Lu M, Wang J, Li Y, Berenzon D, Wang X, Mascarenhas J, $\mathrm{Xu} \mathrm{M}$ and Hoffman R: Treatment with the Bcl-xL inhibitor ABT-737 in combination with interferon $\alpha$ specifically targets JAK2V617F-positive polycythemia vera hematopoietic progenitor cells. Blood 116: 4284-4287, 2010. 